\title{
Letter to the Editor: Medicolegal Sidebar: Informed Consent in the Information Age
}

\author{
Anna Zagaja MA, Rafał K. Patryn JD
}

\section{To the Editor,}

VV e read with interest the Medicolegal Sidebar column on obtaining informed consent in the information age. We agree with the legal doctrine of informed consent, where a doctor must provide enough information to help the patient make enlightened healthcare choices.

Yet physicians frequently omit certain steps in obtaining informed consent. For instance, they often provide insufficient information on harms and risks, do not check if patients understand the

(RE: Bal BS, Brenner LH. Medicolegal sidebar: Informed consent in the information age. Clin Orthop Relat Res. 2015;473:27572761.).

The authors certify that they or any members of their immediate families, have no funding or commercial associations (eg, consultancies, stock ownership, equity interest, patent/licensing arrangements, etc) that might pose a conflict of interest in connection with the submitted article. All ICMJE Conflict of Interest Forms for authors and Clinical Orthopaedics and Related Research ${ }^{\circledR}$ editors and board members are on file with the publication and can be viewed on request.

The opinions expressed are those of the writers, and do not reflect the opinion or policy of $C O R R^{\circledR}$ or The Association of Bone and Joint Surgeons ${ }^{\mathbb{R}}$. provided information, or even ask the nursing staff to obtain the consent for them. Consequently, the patients' outlook or expectations regarding a treatment method may be distorted.

We have a proposal for improving the process. We would emphasize the importance of how consent is obtained (either on a video, recorded, or in writing). By doing so, we would place more responsibility on the physician and his or her obligation of providing the necessary information and receiving a valid, effective, and informed consent from the patient.

It is the physician's job to confirm that the patient comprehends what has been presented. But taking into consideration a patient who is going through an emotional breakdown caused by a progressive disease, it is difficult to expect him or her to make treatment choices based on reading intricate and

\footnotetext{
A. Zagaja MA ( $\varangle)$, R. K. Patryn JD Department of Ethics and Human Philosophy, Medical University of Lublin, S. Staszica 4/6, 20-059 Lublin, Poland

e-mail: anna.zagaja@o2.pl

R. K. Patryn JD

Provincial Committee for Adjudication on Medical Events, Czechowska 15, 20-072 Lublin, Poland
}

extensive forms, analyzing words and phrases, or asking questions. Here, the question of whether the patient is actually capable of making such a decision comes into play. In many cases, the patient is not informed even though, from a medical perspective, the patient has the capacity to make a decision.

The burden of this process should be placed on the physician, who is legally obliged to provide the patient with information and answer any questions or doubts. Only after everything is clear to the patient does the physician have the right to ask for consent, to which the patient can agree or disagree.

We understand that this proposal requiring a written, audio, or video recording of the information "transaction" between the physician and the patient places an additional burden on the physician. But we feel strongly that by doing so, the physician will be obtaining consent from a more-informed patient.

\footnotetext{
Open Access This article is distributed under the terms of the Creative Commons Attribution 4.0 International License (http:// creativecommons.org/licenses/by/4.0/), which permits unrestricted use, distribution, and reproduction in any medium, provided you give appropriate credit to the original author(s) and the source, provide a link to the Creative Commons license, and indicate if changes were made.
} 